\title{
MÍDIA, ECOLOGIA E ÁREAS VERDES: O OESP E OS PARQUES DA GESTÃO SETÚBAL (1975 - 1979)
}

\author{
MEDIA, ECOLOGY AND GREEN AREAS: THE OESP AND THE SETÚBAL \\ MANAGEMENT PARKS(1975-1979)
}

\section{Paula Alessandra Ramos}

Aluna de graduação da Faculdade de Arquitetura e Urbanismo da Universidade de São Paulo (FAUUSP), bolsista de Iniciação Científica da Fundação de Amparo à Pesquisa do Estado de São Paulo (Fapesp) paula.ramos@usp.br

\section{RESUMO}

A criação de parques municipais em São Paulo aconteceu de forma esparsa e pouco eficiente ao longo da história da cidade. A gestão de Olavo Setúbal (1975-1979), no entanto, apresentou um forte contraponto a essa tendência, sendo um período marcado por fortes investimentos no setor. Diversos fatores contribuíram para que a política encampada pelo prefeito obtivesse sucesso. $O$ recorte aqui proposto enfoca a influência do jornal $O$ Estado de São Paulo na consolidação dessa política, buscando elucidar uma etapa importante da produção do espaço público na cidade de São Paulo, em especial as áreas verdes de lazer e recreação, a partir de suas premissas sociais e dos interesses nela implicados.

Palavras-chave: Áreas verdes, parques municipais, política ambiental, Olavo Setúbal, parques urbanos.

\begin{abstract}
The creation of municipal parks in São Paulo has happened on a spread and less efficient way during this city history. The Olavo Setúbal's administration (1975-1979), nevertheless, has showed a strong opposite idea to this aforementioned tendency, it has been a period marked by strong investments in this sector. There were several factors that contributed to the policy were successfully taken over by the mayor. The outline proposed here focuses on the influence of O Estado de São Paulo journal in the consolidation of that policy, trying to elucidate an important step in the production of the public space in São Paulo, especially the green areas for leisure and recreation, from their social assumptions and interests involved in them.
\end{abstract}

Keywords: Green areas, municipal parks, environmental policy, Olavo Setúbal, urban parks.

\section{INTRODUÇÃO}

O provimento de áreas verdes por parte da municipalidade na cidade de São Paulo ocorreu de forma bastante variada ao longo de sua história, a começar pelos jardins públicos, passeios e praças ajardinadas, passando pelas "praças equipadas", até os parques urbanos voltados para o lazer e áreas de proteção ambiental (BARTALINI, 1999). Diversos foram os tratamentos dados a essas áreas e a importância que tiveram nas diferentes administrações municipais. De um modo geral, porém, a intervenção do poder público, nesse sentido, foi bastante ineficiente em São Paulo, ficando a cidade, muitas vezes, carente de áreas verdes destinadas ao lazer.

A década de 1970, no entanto, apresentou um grande contraponto a essa tendência, na medida em que diversos trabalhos foram realizados pela prefeitura, com o intuito 
de estudar meios para aumentar a quantidade de áreas verdes por habitante em toda a cidade, que culminaram na criação de dez parques (Carmo, Anhanguera, Piqueri, Vila dos Remédios, São Domingos, Previdência, Nabuco, Raposo Tavares, Conceição e Pirituba) no período de um único mandato (OLAVO SETÚBAL, 1975-1979).

Grande parte desses parques foi implantada por meio de desapropriação, sendo o parque do Carmo o precursor dessa prática. O então prefeito de São Paulo, Olavo Setúbal, figura até hoje como o governante que mais fez pelo verde na cidade, ainda que essa não fosse a principal meta de seu governo. $\bigcirc$ transporte público e a eficiente administração do orçamento municipal eram suas prioridades.

Essa política de criação de parques ${ }^{1}$ estava apoiada em um leque de planos nacionais voltados para o planejamento urbano. Vultosos investimentos estavam sendo feitos para desenvolver a área periférica de São Paulo, por exemplo, com o intuito de abrigar os grandes contingentes de migrantes. A zona leste foi priorizada por esses investimentos ao ser escolhida como vetor de expansão, o que exigiu que uma série de equipamentos fosse ali implantada, figurando entre eles o Parque do Carmo².

A política de abertura de parques estava também articulada com a política ambiental que se desenvolvia em âmbito nacional que, por sua vez, estava inserida nas discussões internacionais sobre meio ambiente.

Esse período assistia a emergência da questão ambiental no âmbito internacional. Diversos debates, em vários níveis de governo, estavam sendo travados sobre o meio ambiente. A evolução dos conceitos sobre o ambiente natural e os cuidados que esse exigia acontecia de forma rápida. Segundo Santos (2004), nesse período, o meio ambiente e sua conservação passam a ter papel preponderante nas discussões sobre a qualidade de vida da população.

No entanto, apesar da questão ambiental ser inserida nas propostas de desenvolvimento dos governos, por meio do gerenciamento dos recursos e de maior controle ambiental, não aconteceria até a década de 1990 uma mudança de postura diante da utilização dos recursos naturais. Discussões sobre equilíbrio ecológico e manutenção dos ecossistemas estavam apenas começando a ser esboçadas e os problemas sociais não eram sequer mencionados. A preocupação real do período girava em torno de aumentar o desenvolvimento das cidades sem interferir na qualidade de vida. A poluição era tida como um problema chave e a manutenção do verde parecia essencial para diminuir esse problema e influenciar no bem-estar da população.

A redução da discussão internacional à defesa da cobertura vegetal justificava a ênfase da política ambiental brasileira na proteção do verde. O Brasil participava ativamente desses debates por meio da recém-criada Secretaria Especial do Meio Ambiente (SEMA). Seu secretário, Paulo Nogueira Neto, exerceu o cargo entre 1974 e 1986 e foi o grande interlocutor das questões ambientais dentro e fora do país, tendo participado de diversos grupos em favor da ecologia. Mantinha também uma relação de proximidade com a imprensa e afirmava lançar mão do apoio da "opinião pública" para fortalecer a SEMA e as políticas por ela encampadas (BARONE, 2008). 
O entendimento da mídia enquanto poder formador de opinião pública e legitimador de determinadas políticas dentro de um quadro de correlação de forças com o poder público foi a base deste estudo. Procuramos entender quais os fatores a permitirem que uma política de áreas verdes fosse aceita e implementada com tamanha facilidade. Nessa perspectiva, a postura do jornal O Estado de São Paulo (OESP) diante dessas questões foi essencial para a legitimação dos planos de Setúbal com relação à abertura de parques municipais ${ }^{3}$.

Neste trabalho procuramos analisar a posição do periódico relativamente ao meio ambiente, por meio da leitura das notícias do próprio jornal, entre os anos em que Setúbal esteve à frente da prefeitura de São Paulo. A leitura ficou restrita à primeira dezena de cada mês do período por questões de tempo e metodologia e nesse período foram encontradas 216 notícias, que nos permitiram focalizar alguns temas principais, tais como desmatamento, reflorestamento, polvição, ecologia, ocupação agrária e parques. $\bigcirc$ último item tem especial destaque, na medida em que trata diretamente do tema desta pesquisa e, devido à grande quantidade de reportagens encontradas, justifica este estudo e evidencia sua relevância.

\section{DESMATAMENTO}

A preservação do meio ambiente era um assunto de grande importância internacional durante a década de 1970. Segundo Santos (2004), a preocupação com o meio ambiente veio evoluindo com os conceitos adotados no planejamento urbano. Um marco desse processo aconteceu em 1968 com o Clube de Roma ${ }^{4}$, quando o desenvolvimento econômico deixou de ser o foco principal do planejamento das cidades, e a sociedade passou a fazer mais pressão sobre os governos com relação aos problemas ambientais. No entanto, a questão se resumia, basicamente, à preservação das áreas verdes. A discussão só incluiria os problemas sociais e a biodiversidade uma década depois, com o relatório Nosso futuro comum, no qual é cunhado o termo "desenvolvimento sustentável" (COMISSÃO MUNDIAL SOBRE MEIO AMBIENTE E DESENVOLVIMENTO, 1988).

Sendo assim, naquele momento, o desmatamento estava no epicentro do problema ambiental. Também no OESP podemos identificar este como um assunto relevante. Ao todo foram encontradas 66 notícias sobre o assunto, número expressivo, se comparado ao total levantado.

Grande parte dessas reportagens visava denunciar desmatamentos, como no caso da fazenda de lperó, que estava sendo desmatada para a extração de minérios (OESP, mar. 1978, p. 19), ou da Serra do Japi, onde estava ocorrendo a implantação de loteamentos irregulares (OESP, 05 fev. 1978, p. 21).

Nesse conjunto de reportagens, existe um "bloco" especial com 12 reportagens - 11 delas concentradas em apenas quatro meses - que discutem o possível desmatamento de uma única área, a Reserva Florestal de Caucaia do Alto. Essa área, localizada na região metropolitana de São Paulo, foi escolhida pela Secretaria Federal dos Transportes para dar lugar a um novo aeroporto internacional. A revolta gerada entre ecólogos e 
conservacionistas foi tão grande que a decisão foi tomada e revogada diversas vezes. Enquanto os responsáveis pela obra diziam que essa já era uma decisão consumada e a necessidade de construir o equipamento suplantava qualquer questão ecológica (OESP, 07 mar. 1978, p. 23), autoridades ligadas ao setor ambiental admitiam ser necessário que a área fosse melhor estudada e talvez fosse preciso procurar um novo local para essa finalidade (OESP, 04 fev. 1978, p. 11).

Esse episódio da questão ambiental no país é apontado pelo jornal como um catalisador da consciência ecológica, pois gerou diversos protestos da população e resultou na vitória dos conservacionistas, como mostra a última reportagem encontrada sobre o assunto, que comemora a criação de uma reserva florestal na área (OESP, 04 out. 1978 , p. 19). Esse episódio mostra como o jornal fala em nome da população e exalta essa ocorrência como uma grande explosão de consciência ecológica, na tentativa de forjar uma opinião pública sobre o meio ambiente.

Outro bloco de notícias incluído nesse tema e revelando uma faceta importante do entendimento da questão ambiental do período diz respeito à importância dada às árvores. É possível perceber como cada árvore é considerada essencial para o equilíbrio ecológico do planeta. Instituição do Ano da Árvore (OESP, 04 maio 1977, p. 24), levante de estudantes contra a derrubada de um conjunto de árvores dentro do campus de Universidade (OESP, 03 dez. 1978, p. 57) ou punição pela derrubada de coqueiros dentro de uma propriedade particular (OESP, 02 set. 1976, p. 26) são alguns dos assuntos levantados, contabilizando, ao todo, 17 reportagens.

Uma matéria interessante sobre o assunto não cita diretamente as árvores. Fala sobre uma intervenção de artistas de Curitiba, que pintaram outdoors na cidade com motivos ecológicos para atentar a população sobre a necessidade de preservar as florestas. Chama a atenção o fato de todos os desenhos criados mostrarem árvores sendo cortadas (OESP, 02 abr. 1977, p. 14).

Como observado anteriormente, a cobertura vegetal ocupava o foco das discussões e cada árvore tinha singular importância na luta contra a devastação. Tal postura estava em consonância com o que se discutia no restante do mundo. $\bigcirc$ próprio jornal revela essa concordância, ao registrar uma conferência das Nações Unidas que discutiu formas de conter a desertificação em diversos países do mundo e apontou o corte de árvores como o maior responsável pela transformação de 36 milhões de hectares em deserto (OESP, 04 set. 1977, p. 37).

Essa visão é realçada por Paulo Nogueira Neto, ao afirmar: "para os ambientalistas, em primeiro lugar era importante defender as florestas" (TUFFANI, 2007, p. 2). Só posteriormente questões relativas à polvição e também as questões sociais foram agregadas à discussão. Barone (2008) também endossa esse aspecto: "a política ambiental brasileira (...), durante os anos 70, foi marcada por uma orientação de defesa da cobertura vegetal, quase exclusivamente" e "em um país como o Brasil, cujo apelo internacional passava pela constituição da imagem tropical, o discurso fazia muito sentido."

Podemos afirmar, então, que a questão ambiental nesse período ainda estava em desenvolvimento e encontrava-se em um ponto no qual meio ambiente podia ser 
traduzido por cobertura vegetal. Assim, é possível compreender facilmente porque o reflorestamento, assunto do próximo bloco de notícias, é visto como a grande solução para os problemas ambientais.

\section{REFLORESTAMENTO}

Ao todo, 14 reportagens sobre reflorestamento foram encontradas nas páginas do jornal durante o período pesquisado. As reportagens tratam de seus benefícios, de incentivos ficais e de projetos específicos.

$\bigcirc$ investimento do governo é de grande vulto. Para o ano de 1977 foi aprovado um orçamento de R\$3,2 bilhões para empreender o reflorestamento no país, metade da quantia inicialmente proposta pelo Ministério da Agricultura (OESP, 02 jun. 1977, p. 38), além de 10 milhões que seriam utilizados para pesquisas na área (OESP, 05 maio 1977, p. 29). Em 1978 seriam investidos mais 430 milhões só no estado do Mato Grosso (OESP, 07 jun. 1978, p. 15).

Em outra reportagem, OESP deixa claro seu apoio ao reflorestamento. Um contrato entre o IBDF e a Secretaria da Agricultura para estimular o reflorestamento de pequenas propriedades é aplaudido veementemente pelo jornal, que diz não entender por que "medida tão lógica (...) não foi ainda adotada nacionalmente" (OESP, 08 jul. 1978, p. 16).

Mas existem também reportagens nas quais técnicos em meio ambiente criticam a forma como esse reflorestamento é executado. Um técnico afirma que o plantio de árvores no Brasil tem caráter comercial e não de reposição das espécies nativas, o que não poderia, segundo ele, ser chamado de reflorestamento (OESP, 01 jul. 1976, p. 28).

Esse assunto causa incrível polêmica até hoje. Empresas e entidades ligadas ao comércio de insumos para a produção de papel, por exemplo, defendem o reflorestamento como uma forma de conter os avanços sobre áreas de reserva natural e como ação necessária do ponto de vista econômico. Afirmam também que a plantação de espécies exóticas, como o eucalipto, não é prejudicial para o ecossistema dos lugares onde são inseridas. Essa afirmação, entretanto, é contestada por diversas entidades e especialistas os quais afirmam que a presença de grandes áreas de reflorestamento diminui a biodiversidade e serve apenas a fins econômicos.

No entanto, naquele momento, o que se entendia como preservação ambiental no Brasil e no mundo era a conservação de árvores, não importando exatamente qual espécie, conforme mostramos anteriormente. A discussão sobre biodiversidade só ganhou força em meados da década de 1980. Segundo Wilson, um dos maiores estudiosos mundiais do tema, essa mudança de enfoque ocorreu devido ao "acúmulo de dados suficientes sobre desmatamento, espécies em extinção e biologia tropical, que colocou os problemas globais em foco e garantiu uma maior exposição ao público", além de "uma consciência crescente da íntima ligação entre a conservação da biodiversidade e o desenvolvimento econômico" (WILSON, 1997, p. 2).

Sendo assim, esse entendimento do que era o reflorestamento, defendido dentro e fora do país, e a noção que meio ambiente pudesse ser traduzido por cobertura vegetal 
funcionaram como grandes legitimadores da política de reflorestamento adotada aqui, sem nenhuma correspondência com a expansão da área de florestas nativas.

\section{ECOLOGIA}

Segundo Barone, na década de 1970, "falava-se muito mais em 'ecologia' que propriamente em 'meio ambiente" e isso reforçava ainda mais "o caráter pró-proteção da cobertura vegetal, das florestas e matas nativas na concepção do movimento ambiental naquele momento" (BARONE, 2008, mimeo).

Esse fato é reforçado pela grande quantidade de notícias sobre ecologia encontradas no periódico. Ao todo, 27 reportagens falaram sobre debates realizados, denúncias por parte da população, criação de reservas e ensino de ecologia em escolas. Essa quantidade de matérias também revela a tentativa de registrar e difundir, ou até induzir, um suposto crescimento da consciência ecológica e da necessidade de alertar a população sobre a preservação ambiental, por parte do jornal.

A criação de conselhos e associações para a defesa dos recursos naturais é tema recorrente (OESP, 02 mar. 1979, p. 23). A reportagem sobre a introdução da ecologia no programa escolar do Rio Grande do Sul (OESP, 07 out. 1978, p. 19), é uma das várias relacionadas à necessidade de colocar as crianças em contato com o assunto.

Nessas reportagens também é possível observar como o tema (e a própria palavra ecologia) é novo e está em construção, mas mesmo assim é amplamente utilizado. Por exemplo, 14 reportagens trazem a palavra ecologia, ou algum derivado, em suas manchetes. Em uma reportagem especial, a "Ciência Ecológica" aparece como uma disciplina ainda em desenvolvimento, com vistas a fazer a população compreender melhor seus significados (OESP, 07 jun. 1978, p. 8).

Segundo Barone (2008), essa tendência teria influenciado a terminologia adotada na legislação de zoneamento de São Paulo: o que se convencionava chamar de "espaços livres" passou a ser denominado "áreas verdes".

\section{POLUIÇÃO}

Polvição e preservação de florestas naturais também fazem parte das discussões relativas ao meio ambiente no período, de acordo com o material encontrado no jornal. Assim como os demais assuntos, as opiniões relativas a eles ainda eram divergentes e estavam em processo de amadurecimento. Doze reportagens sobre o assunto foram levantadas.

A concentração dessas reportagens é sazonal. No inverno, nota-se uma concentração de matérias sobre esse tema devido ao aumento da polvição do ar. Já o verão concentra reportagens sobre a polvição das praias. No entanto, um assunto é constante nas matérias sobre polvição ambiental: a degradação causada pelas indústrias.

A SEMA é o maior agente nessas reportagens. Em matéria sobre as causas da crise ambiental, o diretor da Divisão de Controle da Poluição, Celso do Amaral, aponta a 
"falta de consideração dos fatores ecológicos nos processos de planejamento" como um dos motivos para o aumento da poluição e da redução no nível de qualidade de vida (OESP, 03 fev. 1976, p. 24).

A poluição do ar causada pelo aumento do número de carros nas ruas (OESP, 06 out. 1976, p. 16) e pelas indústrias (OESP, 02 abr. 1976, p. 40) aparecem como motivos de grande preocupação para a sociedade e os estudiosos do meio ambiente, que questionam e criticam as condições ambientais das cidades.

Essa preocupação era reflexo e estava de acordo com o debate internacional. Segundo Santos (2004, p. 19), a Conferência de Estocolmo, em 1972, foi "um marco na discussão sobre a polvição da água e do ar". O parágrafo três do documento resultante da Conferência registra os "perigosos índices de polvição na água, no ar, na terra e nos seres vivos e os distúrbios grandes e indesejáveis no equilíbrio ecológico da biosfera" (NAÇÕES UNIDAS, 1972, p. 2).

\section{ECOSSISTEMAS}

A segunda metade da década de 1970 foi um marco nas discussões sobre o futuro das grandes florestas do país, sobretudo da Amazônia, mas também do Cerrado. $\bigcirc$ jornal OESP foi grande vinculador desse debate. Cerca de 34 reportagens foram lidas sobre esse tema. Em grande maioria, o foco das discussões é a ocupação agrária e a exploração madeireira dessas regiões. Em um momento em que o país busca um rápido desenvolvimento econômico, essa ocupação parece ser inevitável. No entanto, a preservação ambiental também é uma questão de grande importância no período.

As notícias conjugam as discussões sobre a necessidade de desenvolver a economia nas regiões amazônica e de cerrado e a necessidade de preservar a vegetação existente nessas áreas. Uma das matérias expõe a exploração do cerrado brasileiro como fonte de produção agrícola e a necessidade de pesquisas para que essa exploração ocorra com o mínimo impacto ambiental e o máximo lucro (OESP, 07 mar. 1976, p. 57).

A exploração das florestas encontra defensores nos grandes proprietários de terra. A concepção do Brasil como um país essencialmente agrário fazia com que a utilização dessas matas para fins agropecuários fosse facilmente aceita. E OESP era grande defensor desse postulado. Em uma pesquisa que tem o jornal como objeto, Capelato e Prado o identificam com a perspectiva da classe dominante paulista, grande proprietária de terras. A própria família Mesquita, dona do jornal, possuía terras. No entanto, ainda segundo a autora, "a vinculação estabelecida entre os interesses econômicos particulares dos Mesquita e aqueles defendidos pelo jornal não pode e nem pretende ser direta" (CAPELATO; PRADO, 1980, p. 67). Isso porque a postura do jornal é política, com a finalidade de construir uma discussão coletiva e não apenas de defender seus próprios interesses.

As reportagens mostram também o descaso e os problemas causados pela exploração dos ecossistemas brasileiros. Em uma das matérias sobre o ritmo acelerado da devastação na Amazônia (OESP, p. 26, 07 nov. 1976), mostra que o maior objetivo 
da ocupação era a simples criação de pastagens e a madeira extraída não era ao menos aproveitada.

Um dos motivos desse descuido era a falta de recursos para fiscalização. Ao responder a denúncias feitas por Burle Marx sobre o uso de desfolhantes e o desmatamento na Amazônia, o presidente do IBDF Paulo Berutti afirma que a maior dificuldade existente na proteção às florestas brasileiras "é a falta de contingente para fiscalização e também sua falta de treinamento". Essa fala é ampliada por Paulo Nogueira Neto, secretário da SEMA, ao afirmar: "a fiscalização é o ponto essencial da preservação e que uma exploração contínua e racional da Amazônia é a chave para tirar proveito da floresta sem destruir o equilíbrio ecológico." (OESP, 05 fev. 1976, p. 16)

As maiores críticas à ocupação das florestas vêm de especialistas internacionais. Para Harald Sioli, se o ritmo da devastação fosse mantido, a Amazônia acabaria em setembro de 2003. Ele sugere pesquisas de controle biológico, reservas florestais, reflorestamento com espécies nativas ao invés de eucalipto e a educação ambiental como formas de preservar a floresta (OESP, 03 jun. 1976, p. 24). É internacional também a maior parte do apoio financeiro e tecnológico para pesquisas realizadas tanto no Cerrado quanto na Amazônia. A reportagem "EUA vão ajudar a preservar" expõe os projetos patrocinados por aquele país, como proteção da fauna e criação de Parques Nacionais para a preservação de ecossistemas (OESP, 07 ago. 1976, p. 15).

Pode-se entender, então, que a preocupação em preservar as florestas nacionais sofre a influência e é legitimada por organismos internacionais, ao passo que, internamente, a defesa da vocação essencialmente agrária do país incentiva e estimula a exploração das mesmas para cumprir os ideais de desenvolvimento estabelecidos. Isso é compreensível e torna-se justificado, pois, observando as demais reportagens e a bibliografia de referência, concluímos que aquilo que realmente importava era preservar o "verde", podendo isso significar desde matas nativas até uma monocultura.

\section{PARQUES}

Entender a razão de tantos parques municipais serem criados no tempo de um único mandato e o papel do jornal OESP na consolidação dessa política foi o objetivo que originou este artigo. A grande quantidade de notícias encontradas especificamente sobre esse tema demonstra que a questão era de grande importância e o jornal estava diretamente engajado nela, dando uma nova pertinência ao assunto. Ao todo foram encontradas 63 matérias relacionadas a parques, e 26 falavam diretamente dos parques municipais criados por Setúbal.

A abertura de parques já era um assunto em pauta nos anos anteriores ao mandato de Setúbal: no município de São Paulo, o problema vinha sendo tratado pela prefeitura desde o final da década de 1960. Internacionalmente, a bibliografia aponta a pertinência desse debate desde o final do século 18. Foi nesse período que o parque surgiu como fato urbano relevante na Inglaterra, desenvolvendo-se plenamente durante o século seguinte (CHADWICK, 1966). Segundo Bartalini (1995), áreas particulares 
eram abertas ao público por algumas horas em determinados dias da semana, tendo como objetivo principal oferecer à população espaços para passeios e contemplação. Também na França, antigas propriedades reais foram abertas ao uso público, como o Jardim das Tuilleries, em Paris. Esses espaços eram utilizados para o exercício da sociabilidade e para o ato de exibição mútua entre as diversas classes que os frequentavam (SENNET, 1988).

Nas cidades americanas, o movimento em favor dos parques esboça-se a partir de 1840 e tem em Olmsted seu principal defensor. Para ele, o parque era considerado "um sinônimo de justiça social e de participação democrática (...), um instrumento de nivelamento social e de educação do povo para a responsabilidade coletiva do bem estar" (DAL CO, 1975, p. 8). Já para Harvey (1982), a discussão girava em torno da necessidade de atenuar as condições degradantes de trabalho nas fábricas pela provisão de espaços de contemplação e relaxamento. Segundo ele, os parques foram uma resposta à necessidade de "promover uma sensação de contentamento e satisfação na força de trabalho, de maneira a leva-la à cooperação espontânea e à eficiência" (SENNET, p. 29).

Em São Paulo, estudos sobre a necessidade de aumentar a quantidade de áreas verdes por habitante foram feitos desde 1967 (KLIASS et al, 1967; COGEP, 1974, 1975 a e 1975b). Esses documentos trazem dados técnicos sobre o assunto, como a quantidade de árvores a plantar, o tamanho das áreas a serem criadas e o valor desses investimentos. As áreas verdes seriam a melhor forma de minimizar as condições insalubres da cidade e de conter a polvição. Elas eram vistas também como fator de extrema importância para a sobrevivência da metrópole, "pela influência que exercem sobre a saúde, mental e física, de todos os seus habitantes" (COGEP, 1974, p. 6). 0 levantamento realizado por Kliass (1967) traz ainda a dimensão social dos espaços livres, considerados "um dos fatores de maior importância para a polarização das atividades urbanas, visando uma nova coesão social" (COGEP, p. 4).

No entanto, esses planos se concretizaram apenas no mandato de Setúbal. E o apoio do jornal ao prefeito foi de grande importância para a consolidação da política de abertura de parques por ele encampada, na medida em que conseguia colocar a opinião pública a favor dessa ação. É possível identificar esse apoio nos elogios do jornal a iniciativas similares, como na reportagem na qual as prefeituras de Diadema e Ribeirão Preto são comparadas. A primeira recebeu duras críticas e teve seu prefeito acusado de abandonar as duas últimas áreas verdes restantes na cidade, apesar da promessa de criar parques municipais em tais áreas. Enquanto isso, inúmeros elogios foram feitos à iniciativa da prefeitura de Ribeirão, que estava investindo na criação de um parque ecológico por meio de desapropriações (OESP, 03 mar. 1979, p. 21).

Esse apoio é perceptível também na quantidade de reportagens relativas ao futuro parque Anhanguera, criado por Setúbal. Foram oito reportagens ao longo de um ano, número ainda mais expressivo, se levarmos em consideração que apenas o primeiro terço de cada mês foi levantado, como explicado anteriormente. $\bigcirc$ parque do Carmo também foi assunto constante no jornal, sendo verificadas notícias que iam desde a 
construção de um novo acesso ao parque (OESP, 04 mar. 1979, p. 38) até sua importância como espaço a ser utilizado nos fins de semana. (OESP, 06 jun. 1977, p. 14).

P parque do Carmo traz consigo, ainda, uma outra questão, relativa à utilização da desapropriação como meio principal de obter as áreas para os parques. Diversos parques foram abertos por meio desse instrumento e o parque do Carmo é emblemático por ter sido o primeiro.

A aprovação dessa forma de criação de parques era polêmica. $\bigcirc$ prefeito anterior, Miguel Coluassuono, defendia posição contrária à desapropriação para esse fim, afirmando que a prefeitura possuía diversos espaços onde poderiam ser implantados parques e o uso dessas áreas geraria uma grande economia de recursos (COGEP, 1974). No caso do parque do Carmo, destaca-se que a área não precisaria ser desapropriada, iá que a legislação previa a doação de 20\% da gleba loteada ao município, correspondendo justamente à área do parque (BARONE, 2007).

Mesmo assim, essa prática foi "defendida e apoiada" pela opinião pública. No mesmo período, a política nacional do meio ambiente levada a cabo pelo secretário Nogueira Neto também se valia da compra ou desapropriação de áreas para a preservação do verde, chegando até mesmo a comprar cada uma das árvores existentes em um bosque para a implantação de uma estação ecológica (BARONE, 2008, mimeo).

Nas páginas do jornal também se apresentam a finalidade desses parques e sua relação com a discussão ambiental que estava sendo travada em âmbito internacional. Apesar de suprir a sempre lembrada necessidade que os trabalhadores tinham de lazer, a principal função dos parques urbanos, segundo o jornal, era manter espaços verdes e livres no interior da cidade. A expressão "pulmão verde" é constantemente utilizada, como em "Preservar o que ainda for possível" (OESP, 03 ago. 1978, p. 20). A prática de esportes é colocada em segundo plano, como podemos observar em reportagem que narra a não aprovação de Setúbal ao primeiro projeto apresentado para o Parque Anhanguera. Esse projeto previa diversas opções de lazer recreativo e prática de esportes, mas Setúbal o considerou "faraônico" e ordenou que o parque fosse "o mais natural e contemplativo possível" (OESP, 01 jan. 1978, p. 23).

Kliass (1993) observa que o potencial paisagístico é o primeiro fator considerado no projeto de um parque e a grande maioria dos projetos se limita a áreas verdes de contemplação e descanso. Isso pode ser observado também nos documentos produzidos pela Coordenadoria Geral de Planejamento (COGEP). No relatório gerado pela Coordenadoria em 1974, grande ênfase foi dada à importância das áreas verdes "na busca de melhor nível de vida em termos de conforto urbano" (COGEP, 1974, p. 1), sendo os equipamentos de lazer apenas uma forma de "intensificar o hábito de consumo do verde" (COGEP, 1974, p. 18).

Corrobora também essa hipótese a exígua quantidade de reportagens relativas ao lazer não contemplativo. Apenas três foram encontradas em todo o período pesquisado. A primeira data do dia 9 de setembro de 1976 e traz a opinião de arquitetos, que afirmam ser o lazer uma necessidade primária do homem e indispensável para uma boa qualidade de vida. No entanto, segundo eles, a visão tecnicista que 
governava o mundo vinha colocando o lazer no final da lista de prioridades (OESP, 09 set. 1976, p. 29).

Enquanto isso, duas matérias de 1978 mostravam lados opostos da mesma questão. Uma anunciava os planos da prefeitura de criar possibilidades e incentivar a prática de esportes e o lazer recreativo, com campeonatos desportivos, caminhadas e concursos de redação, por exemplo (OESP, 01 jan. 1978, p. 23). A outra denunciava o descaso da mesma prefeitura com os centros esportivos, que se encontravam em péssimo estado de conservação e sofriam falta de funcionários e professores (OESP, 03 dez. 1978, p. 58).

Uma questão é comum às duas matérias: a predominância das camadas mais altas da população na prática de esportes e na utilização dos recursos providos pela prefeitura. Na primeira reportagem, a prefeitura relata que vai incentivar a prática de aeromodelismo e arco e flecha, esportes sabidamente elitistas. Já na matéria sobre os centros esportivos, cita-se que eles são melhor conservados e supridos nos bairros de melhor poder aquisitivo, e nesses centros apenas $30 \%$ dos usuários não têm realmente condições de frequentar clubes particulares. É possível observar essa mesma conclusão em todos os documentos produzidos pela Cogep sobre os parques no período.

Outro aspecto referente à abertura de parques por Setúbal traz uma inquietação: sua localização na periferia. A grande maioria de seus parques foi implantada nessa região, indo contra a prática comum de privilegiar as áreas mais abastadas. Essa característica poderia estar ligada ao fato de as discussões sobre a periferia ganharem cada vez mais destaque a partir da década de 1970.

Diversos autores discutiam os processos de crescimento da periferia e sua vinculação com a espoliação dos meios de subsistência dos trabalhadores. Esse processo também estava vinculado, segundo Telles (1988), ao deslocamento do movimento operário das fábricas para os bairros, que mudou o foco das reivindicações das questões trabalhistas para as condições de vida nos locais de moradia. Além disso, a expansão da cidade em direção à zona leste, já citada anteriormente, fez com que grande soma de investimentos fosse direcionada para essa região.

Considerando todas as questões citadas anteriormente, podemos confirmar a hipótese da singularidade do período relativamente à criação de parques municipais na cidade de São Paulo.

A consolidação de uma política ambiental em âmbito nacional servia como pano de fundo para a iniciativa de Setúbal, dando a ela uma grande pertinência. Além disso, justamente nessa década emerge com grande força a questão ambiental internacional. Os parques criados por Setúbal estavam em consonância com o que era pensado no mundo, na medida em que a concepção de problema ambiental estava restrita à criação e conservação de espaços verdes. A ênfase dada ao crescimento da periferia justificava também a alocação desses parques na região periférica da cidade, criando mais uma situação favorável à implantação dessa política nesses moldes.

Dessa forma, o debate sobre a criação de parques que já estava em marcha nos anos anteriores ao mandato de Setúbal, como podemos verificar nos documentos produzidos pela prefeitura, ganha espaço para se consolidar. A leitura e sistematização das 
notícias encontradas no jornal nos permitiu observar como a presença do OESP nas discussões ambientais e na formação de uma opinião pública pode ter atuado para o sucesso daquela política.

Um primeiro fato é o aumento da quantidade de notícias sobre meio ambiente ao longo do período analisado, indicando um crescente interesse do jornal em relação a essa questão. É possível perceber como o OESP estava antenado nas discussões que ocorriam no mundo, difundindo esse debate de forma bastante efusiva. A importância de manter espaços verdes dentro da área urbana como forma de melhorar a qualidade de vida estava no centro dessa questão.

Algumas reportagens nos permitem ainda perceber como essas idéias acordavam com a defesa de certos interesses por parte do jornal. A visão do Brasil como um país "verde", que precisava defender suas florestas e, principalmente, suas árvores, concordava com o interesse de alguns setores de apoiar o desenvolvimento do país em bases agrárias. Além disso, pode-se observar como o jornal procurava construir a perspectiva que essas ideias eram aceitas e defendidas por toda a população, forjando, assim, uma opinião pública.

A defesa desses interesses por parte do OESP atuou de forma decisiva para a formação de uma opinião pública favorável à política de Setúbal e o apoio da opinião pública é sempre importante para a consolidação de programas propostos pelos governos.

Assim, devemos considerar que uma série de fatores corroborou para que, na década de 1970, acontecesse um aumento significativo na criação de áreas verdes na cidade de São Paulo. A articulação entre os interesses do jornal e os planos de Setúbal foi um desses fatores e parece ter sido de especial importância para o sucesso da empreitada do prefeito.

\section{Notas}

(1) Designaremos, neste artigo, a prática de criação de áreas verdes durante a década de 1970 como uma política pública municipal, embora acreditemos que a qualificação dessa prática como tal ainda seja um problema em aberto.

(2) $\bigcirc$ reconhecimento do rápido crescimento da cidade e a intenção de adensar a zona leste, com investimentos e obras na região, pode ser observado nas conclusões do Plano Urbanístico Básico (PUB), de 1968, que privilegia a zona leste como "vetor urbano de estocagem de mão de obra".

(3) O OESP esteve notadamente engajado nas discussões ambientais ao longo de toda a sua história, apresentando uma orientação para essa questão até os dias de hoje, o que faz dele uma fonte importante para o entendimento da questão.

(4) $O$ Clube de Roma foi uma reunião com notáveis de diversos países e diversas áreas de estudo que resultou no relatório Limites do crescimento, no qual foram discutidos o uso dos recursos naturais e o futuro da humanidade.

Obs.: Este artigo é resultado de uma pesquisa de iniciação científica realizada entre 2009 e 2010 com apoio da Fapesp e orientada pela Profa. Dra. Ana Cláudia Castilho Barone, da FAUUSP.

\section{Bibliografia}

BARONE, A. C. Parque do Carmo (1976): um parque popular na periferia da metrópole. São Paulo, 2007, mimeo.

. Parques urbanos municipais em São Paulo e política ambiental no Brasil na década de 70. In: FERREIRA

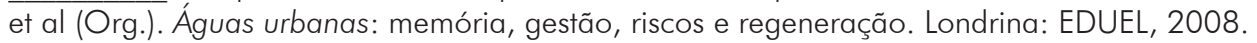


BARTALINI, V. Parques públicos municipais de São Paulo. 1999. Tese (Doutorado) - Faculdade de Arquitetura e Urbanismo, Universidade de São Paulo, São Paulo, 1999.

Sintonias e defasagens - os parques públicos nos planos para São Paulo. Paisagem e Ambiente: ensaios. São Paulo: FAUUSP, n. 7, p. 69-89, 1995.

CAMARGO, C. P. F. et al. São Paulo 1975, crescimento e pobreza. São Paulo: Loyola, 1981.

CAPELATO, M. H.; PRADO, M. L. O bravo matutino: imprensa e ideologia no jornal O Estado de São Paulo. São Paulo: Alfa-Omega, 1980.

CHADWICK, G. F. The park and the town. Londres: The Architectural Press, 1966.

COGEP. Áreas verdes declaradas de utilidade pública. São Paulo: PMSP, 1975. . Política do verde para a cidade de São Paulo. São Paulo: PMSP, 1974. Relatório preliminar, Implantação PAV_01 (programa de áreas verdes). São Paulo: PMSP, 1975.

COMISSÃO MUNDIAL SOBRE MEIO AMBIENTE E DESENVOLVIMENTO. Nosso futuro comum. Rio de Janeiro: FGV, 1988.

CONFERÊNCIA DAS NAÇÕES UNIDAS. Declaração de Estocolmo sobre o meio ambiente humano. 1972. Disponível em: http://www.mudancasclimaticas.andi.org.br/node/90. Acesso em: 16 mar. 2010.

DAL CO, F. Dos parques à região. Ideologia progressista e reforma da cidade americana. In: CIUCCl, G. La ciudad americana, de la guerra civil al New Deal. Tradução livre de Ana Cláudia Castilho Barone. Barcelona: Gustavo Gilli, 1975.

HARVEY, D. O trabalho, o capital e o conflito de classes em torno do ambiente construído nas sociedades capitalistas avançadas. Espaços e Debates. São Paulo: Cortez, n. 6, 1982.

KLIASS, R. G. (et al). Levantamentos: características urbanas de 5 zonas de aproximadamente 25 km². São Paulo: PMSP, 1967.

Parques urbanos de São Paulo e sua evolução na cidade. São Paulo: PINI, 1993.

KOWARICK, L. A espoliação urbana. Rio de Janeiro: Paz e Terra, 1979.

MAGNOLI, M. M. O parque no desenho urbano. Paisagem e Ambiente: ensaios. São Paulo: FAUUSP, n. $21,2006$.

NIEMEYER, C. A. C. Parques infantis de São Paulo - lazer como expressão de cidadania. São Paulo: Annablume; Fapesp, 2002

OLIVEIRA, F. O estado e o urbano no Brasil. Espaço e Debates, São Paulo, p. 36-54, 1982.

ROLNIK, R.; BONDUKI, N. Periferia da grande São Paulo, reprodução do espaço como expediente de reprodução da força de trabalho. In: MARICATO, Ermínia. A produção capitalista da casa (e da cidade) no Brasil industrial. São Paulo: Alfa-Omega, 1982.

SANTOS, R. F. Planejamento ambiental, teoria e prática. São Paulo: Oficina de textos, 2004.

SINGER, P. Desenvolvimento econômico e evolução urbana. São Paulo: Nacional, 1968.

Economia política da urbanização. São Paulo: Brasiliense, 1973.

SCALISE, W. Parques urbanos - evolução, projeto, funções e uso. Revista Assentamentos Humanos, v. 4, n. 1. Marília, p. 17-24, 2002.

SENNET, R. O declínio do homem público: as tiranias da intimidade. Tradução de Lygia Araújo Watanabe. São Paulo: Cia. das Letras, 1988.

TELLES, V. S. Anos 70: experiências, práticas e espaços políticos. In: KOWARICK, L. (Coord.). As lutas sociais e a cidade: São Paulo, passado e presente. Rio de Janeiro: Paz e Terra, 1988.

TUFFANI, M. Há esperança para a qualidade de vida. Galileu. Disponível em: http://revistagalileu.globo.com/Galile u/0,6993,ECT444027-1718-2,00.html. Acesso em: 13 jul. 2010.

WILSON, E. O. (Org.). Biodiversidade. Rio de Janeiro: Nova Fronteira, 1997.

Diversidade de vida. São Paulo: Cia das Letras, 1994. 


\section{Reportagens do jornal O Estado de São Paulo}

"A ciência ecológica: a preservação dos recursos naturais", 07 jun. 1978, p. 8;

"A polícia denuncia novo desmatamento", 08 mar. 1978, p. 19;

"Artistas saem à rua em defesa da ecologia", 02 abr. 1977, p. 14;

"Árvores que não podem ser derrubadas", 18 jan. 1976, p. 34;

"Assembleia aprova reserva em Caucaia", 04 out. 1978, p. 19;

"Caucaia, a explosão da consciência ecológica", 5 mar. 1978, p. 36;

"Cerrados dobram riqueza agrícola do país", 07 mar. 1976, p. 57;

"Conter desertos é a meta", 04 set. 1977, p. 37;

"Devastação cresce na Amazônia", 07 nov. 1976, p. 26;

"Ecologia já é ensinada aos escolares gaúchos", 07 out. 1978, p. 19;

"Em 2003 o fim da floresta", 03 jun. 1976, p. 24;

"EUA vão ajudar a preservar", 07 ago. 1976, p. 15;

"Eucalipto, o passado comum", 01 jan. 1978, p. 23;

"Expansão ameaça Serra do Japi", 05 fev. 1978, p. 21;

"Floresta, questão secundária", 07 mar. 1978, p. 23;

"Gaúchos querem salvar palmeiras e apelam para o IBDF", 04 set. 1976, p. 18;

"IBDF decide punir corte", 02 set. 1976, p. 26;

"IBDF investiga uso de desfolhante na Amazônia", 05 fev. 1976, p. 16;

"IBDF investirá 430 milhões em Mato Grosso", 07 jun. 1978, p. 15;

"Instituído dia da árvore no Rio Grande do Sul", 04 maio 1977, p. 24;

"Jundiaí cria conselho para defender ecologia", 02 mar. 1979, p. 23;

"Lançada campanha", 02 set. 1976, p. 26;

"Lazer, algo além de televisão e restaurantes", 01 jan. 1978, p. 23;

"Nos centros, o lazer cada vez mais difícil", 03 dez. 1978, p. 58;

"Novo programa vai organizar a pesquisa florestal", 05 maio 1977, p. 29;

"ONU teme polvição de carros", 06 out. 1976, p. 16;

"Para os arquitetos, lazer é prioritário", 09 set. 1976, p. 29;

"Parque do Carmo já tem novo acesso", 04 mar. 1979, p. 38;

"Parque do Carmo, opção para as férias", 06 jul. 1977, p. 14;

"Parques, reservas e áreas verdes", 03 mar. 1979, p. 21;

"Política ameaça área verde", 02 ago. 1976, p. 24;

"Poluição não vai deter a indústria", 02 abr. 1976, p. 40;

"Preservar o que ainda for possível", 03 ago. 1978, p. 20;

"Protesto salva árvores", 03 dez. 1978, p. 57;

"Reflorestamento de pequenas propriedades", 08 jul. 1978, p. 16;

"Reflorestamento vai ter Cr\$3,2 bilhões", 02 jun. 1977, p. 38;

"SEMA aponta as causas da crise ambiental", 03 fev. 1976, p. 24;

"SEMA se propõe a oferecer alternativas para Caucaia", 04 fev. 1978, p. 11;

"Técnico condena a 'indústria' do reflorestamento", 01 jul. 1976, p. 28;

"Um ano depois, a Sé já é mais que uma praça", 03 fev. 1979, p. 46;

"Votuporanga cria entidade para preservar a natureza", 08 nov. 1978, p. 21 ; 